BIRGIT ERIKSSON

Lektor i Astetik og Kultur ved Institut for Astetik

og Kommunikation, Aarhus Universitet

\title{
MELLEM KOMMUNIKATION OG KREATIVITET DELTAGELSE SOM AESTETIKKENS MISSING LINK?
}

\begin{abstract}
BETWEEN AESTHETIC COMMUNICATION AND CREATIVITY - PARTICIPATION AS THE MISSING LINK? I The French philosopher Yves Michaud modernity has characterised modernity by three utopias: the utopia of democratic citizenship, which deals with freedom and equality; the utopia of labour, which deals with social change; and the utopia of art, which deals with inter-subjective communication and community. He has argued that the utopia of art, which since the late 18th century has been closely linked to the utopia of democratic citizenship, is coming to an end. Building upon this argument, the article examines two opposing tendencies in contemporary art and culture: On the one hand, the creativity and promise of novelty, traditionally belonging to the art world, has spread culturally, and creativity is often represented as the most important tool for individual and social change. On the other hand, the idea of art as sustaining participation has been revitalized in the art world by the "relational" or "social" aesthetics, and the "dialogical" or "participatory" art of the last 20 years. But how do these tendencies relate to the modern utopia of art - and to each other? What are the problems inherent in relating art to beautiful ideals of community and creativity, and (how) can the recent focus on aesthetic participation transgress these problems? The article examines these questions, drawing on theories and an analysis of contemporary culture.
\end{abstract}

KEYWORDS I particpation; aesthetics; participatory art; creativity; communication; social change; community; flexibility; inequality; utopia

Den franske filosof og kunstteoretiker Yves Michaud har argumenteret for, at moderniteten er karakteriseret ved tre utopier: utopien om demokratisk medborgerskab, arbejdets utopi og kunstens utopi. Kunstens utopi sporer han tilbage til Immanuel Kants æstetik og hans forestilling om, at vi i kommunikationen om den æstetiske erfaring deltager i og bidrager til at realisere et intersubjektivt menneskeligt fællesskab. Ifølge Michaud er denne indflydelsesrige utopi og dens forbindelse til utopien om det demokratiske medborgerskab ved at forsvinde.

Denne artikel tager udgangspunkt i Michauds tese, som tilsyneladende bekræftes, når det i mange kulturelle sammenhænge ikke er kunstens potentiale for 
kommunikation og fællesskab, der præsenteres som dens vigtigste kvalitet. I mange aktuelle diskurser er det en anden af de egenskaber, der traditionelt forbindes med kunst, der fremstår som den vigtigste: Nu er det især det kreative i kunst, der fremstilles som afgørende for at fremme vores individuelle og samfundsmæssige udvikling.

Mens der i samtidskulturen bredt forstået fokuseres mere på kunst som generator for kreativitet end for fællesskab, sker der tilsyneladende noget andet i samtidskunsten og teorierne omkring den. Således er der i de sidste 20 års kunst og æstetikteori sket en revitalisering af forestillingen om, at man i kunst kan udvikle nye deltagelsesformer. Det sker under overskrifter som relationel æstetik, social æstetik, dialogisk kunst, participatorisk kunst etc.

Men hvordan hænger disse to hhv. kulturelle og kunstneriske udviklingstendenser sammen? Er der en modsætning mellem en kulturel opprioritering af kreativiteten over fællesskabet og en kunstnerisk interesse for deltagelse? Hvilke problemer og modsætninger ligger der $\mathrm{i}$ at forbinde kunst med de smukke idealer om hhv. fællesskab og kreativitet, og hvordan kan vi forstå det aktuelle fokus på deltagelsens æstetik i forhold til disse modsætninger? I artiklen undersøges disse spørgsmål i en samtidsdiagnose, der dels er teoretisk, dels inddrager konkrete eksempler på de modsatrettede tendenser.

\section{Kommunikation og fallesskab}

I "The End of Utopia of Art", en oversættelse af det sidste kapitel i La Crise de'l Art Contemporain, karakteriserer Yves Michaud moderniteten ved dens tre utopier: Utopien om demokratisk medborgerskab handler om frihed og lighed. Arbejdets utopi er centreret omkring social forandring. Og kunstens utopi drejer sig om mellemmenneskelig kommunikation og fællesskab. Disse utopier er relateret til hinanden, og ifølge Michaud har de to utopier om hhv. kunst og demokratisk medborgerskab været tæt forbundet, siden de opstod i slutningen af det I8. århundrede. Forbindelsen sporer han tilbage til Kants idé om erkendelseskræfternes frie spil i den æstetiske tilstand. I I79o beskrev Kant i Kritik af dømmekraften, hvordan vi, når vi fremsiger æstetiske domme, kommunikerer den mentale tilstand, vi er i, når vores erkendelseskræfter er i frit spil. Ved at dele denne tilstand kan vi, hævdede han, forestille os en slags ideel socialitet, hvor vi fri for partikulære interesser og givne begreber etablerer en kommunikativ offentlighed omkring det skønne.

Ifølge Michaud var hovedambitionen med Kants tredje kritik netop dette: at adressere spørgsmålet om kommunikation og fællesskab. Det vigtige var ikke specifikke kunstværker, men at vi ved at kommunikere om den æstetiske erfaring rækker ud mod en "subjektiv universalitet" og dermed både deltager i og bidrager til at realisere et intersubjektivt menneskeligt fællesskab. Ved at frigøre os fra personlige og sociale begrænsninger kan kommunikationen om det æstetiske civilisere og kvalificere selv jævne folk til politisk frihed og lighed. Dermed er kunstens utopi ikke bare en kommunikativ, men også en demokratisk og civilisatorisk utopi, indlejret i oplysningstidens og den franske revolutions store frigørelsesprojekt - i det, Michaud kalder modernitetens utopi om demokratisk medborgerskab.

Michauds pointe er nu, at kunstens utopi og løfte om intersubjektivt fællesskab har vist sig at være en illusion. I den reelt eksisterende æstetiske kommunikation er det ikke sensus communis eller almenhed, der springer i øjnene, men snarere adskillelser mellem forskellige kulturer, klasser og grupper. Dette var, kan man indvende, Kant selv udmærket klar over. Han hævdede ikke, at alle var eller ville blive enige om deres æstetiske domme. (Forestillingen om) en sensus communis var ifølge ham ikke resultatet af, men udgangspunktet for kommunikationen om den æstetiske erfaring. Denne indvending ændrer dog ikke ved, at det store fællesskabspotentiale kan være særdeles svært at få øje på. Problemerne med at indfri kunstens løfte om at inkludere alle i en fællesmenneskelig kommunikation er iøjnefaldende, hvis vi ser på så forskellige felter som kulturpolitik, smagsfællesskaber, marketing og internettet.

I kulturpolitikken, såvel i Danmark som i andre lande, er det trods alle gode intentioner ikke lykkedes at inkludere alle i kunstens løfte om fællesskab og en bedre verden. Trods årtiers afprøvning af forskellige kulturpolitiske inklusionsstrategier er der stadig en social skævhed i interessen for kunst.

I 1960'ernes "demokratisering af kulturen" var strategien at gøre en relativt snæver enhedskultur tilgængelig for alle, først og fremmest ved at mindske de økonomiske og geografiske forhindringer for at få kunstoplevelser. Fra 1970'erne voksede erkendelsen af, at forhindringerne ikke kun var økonomiske og geografiske, men også skyldtes den snævre enhedskulturelle opfattelse af, hvad kultur og kvalitet var. Det førte til en ny strategi, et decentraliseret og kulturpluralistisk "kulturelt demokrati", som i højere grad vægtede medbestemmelse og aktiv deltagelse. Fra I980'erne blev det kulturelle demokrati delvist overskygget af en mere eksplicit instrumentel kulturpolitik, hvor de klassiske mål om demokrati og dannelse tabte terræn til mere specifikke formål, der både kunne være at styrke den nationale konkurrenceevne og at sikre social inklusion og dermed mindske arbejdsløshed, marginalisering, kriminalitet o.l. Siden I990’erne er ønsket om social inklusion italesat under begrebet "publikumsudvikling", der som strategi trækker på elementer i både det kulturelle demokrati og den instrumentelle kulturpolitik (Ejgod IO-II). Fokuseringen på publikum har også bredt sig til Danmark, hvor såvel Kulturministeriet som kulturinstitutioner de seneste år har præsenteret en række "out reach-tiltag", der forsøger at overskride de traditionelle rammer for kunstproduktion og -formidling og inddrage eksisterende og nye brugergrupper i nye kunstneriske oplevelser (Reach Out, Reach Out Inspirationskatalog).

Uligheden er dog ikke forsvundet, og mange mennesker synes uinteresserede i kunstneriske oplevelser. Ikke mindst har kulturpolitikken og -institutionerne det problem, at de jævne folk, som Kant gerne ville civilisere, stadig ikke deltager i kulturlivet - eller oversat til nudansk: folk med lav indtægt og kort uddannelse samt befolkningen i områder langt fra større byer (Danskernes kulturvaner 20I2 I3-I9). 
En væsentlig del af befolkningen (normalt omkring $20 \%$, afhængigt af hvad man måler på) indgår ikke i de kulturelle sammenhænge og udvekslinger, der spørges til i kulturvaneundersøgelser. Og oftest er begrundelsen, at "det interesserer mig ikke" (Ibid. 329).

Studerer man konkrete smagsfallesskaber, er det heller ikke universel kommunikerbarhed og sympati, der er mest iøjnefaldende. Kultursociologien og kulturstudierne har de sidste 40 år bugnet med forskning, der viser, hvordan (kommunikation om) æstetiske præferencer og normer ikke overskrider skel mellem klasser, kulturer osv., men snarere synes at bekræfte og endda forstærke disse. Dette gælder, hvad enten man i traditionen efter Pierre Bourdieu forstår de forskellige smagskulturer som distinktioner i et symbolsk magthierarki, man som Gerhard Schulze ser dem som en horisontal opdeling $i$ adskilte livsstile, eller man i cultural studies-traditionen fokuserer på mere marginaliserede og oppositionelle delkulturer, defineret af f.eks. klasse, køn, etnicitet eller seksualitet. I alle disse kulturstudier udforsker man de specifikke kvalitetskriterier og kommunikationsformer, der kendertegner bestemte smagskulturer, og lægger dermed im- eller eksplicit afstand til forestillingen om smagens almenhed.

Går man ud over et snævert kunstfelt og analyserer æstetiske præferencer i et marketingperspektiv, er der heller ikke umiddelbart stor grund til optimisme på fællesskabets vegne. I hvert fald synes markedet i stadig højere grad at indrette sig på og dermed også at fremme en stærkt segmenteret smag. Således har marketingforskere, som i begyndelsen af I980'erne inddelte USA's familier efter ni forskellige livsstile, $\mathrm{i}$ slutningen af 1990'erne identificeret 62 distinkte livsstile. Det interessante i denne sammenhæng er ikke, om de har ret i en sådan opdeling, men snarere hvordan det påvirker smagsfællesskaberne, når nichecasting afløser broadcasting i reklamer og medier, og kommunikation og produkter i stigende grad rettes mod specifikke målgrupper. Hvis, som Kant argumenterede for, forestillingen om et potentielt universelt fællesskab selv kunne være med til at realisere dette fællesskab, så kan mediernes og marketingseksperternes aktuelle inddeling af os i distinkte livsstile utvivlsomt også være med til at adskille os. At fællesskaber er forestillede, forhindrer dem på ingen måde i at være særdeles virkningsfulde (Anderson).

Adskillelsen i segmenter eller delkulturer forstærkes i ekstrem grad af det, som Eli Pariser kalder internettets "filterboble". I The Filter Bubble: What the Internet is Hiding from You viser han, hvordan væksten i personaliserede og annoncestyrede søgefiltre indskrænker den verden, vi møder på nettet, og strømliner den i forhold til det, vi allerede kender og interesserer os for. Hvad enten det drejer sig om informationssøgning, sociale netværk, musik, film eller andet forbrug online, så indsamler filtrene en voldsomt stigende mængde data om vores egne og ligesindedes online-aktiviteter. Ud fra disse ekstrapolerer filtrene, hvad vi kan forventes at lide. Problemet med disse individualiserede søgefiltre er i endnu højere grad end marketingseksperternes 62 livsstile, at de placerer os i usynlige bobler eller rettere tunneller af information, hvor vi får bekræftet og forstærket vores allerede eksisterende interesser, smagspræferencer og blinde vinkler. Resultatet af disse tunneller bliver let, at vi ikke møder det uventede eller ser den mangfoldighed, som det er nødvendigt at forholde sig til, hvis forestillingen om fællesskab eller demokrati skal kunne inkludere andre end dem, der allerede til forveksling ligner os selv.

\section{Kreativitet, arbejde og forandring}

Ovenstående hierarkier, adskillelser og segmenteringer i smagskulturer er naturligvis ikke enden på kunst. Men i forlængelse af Michauds analyse kan de ses som et tegn på svækkelsen af en bestemt representation af kunsten: af kunstens utopi om kommunikation og fællesskab og dermed også af dens privilegerede relation til utopien om demokratisk medborgerskab. Betyder det så, som Michaud hævder, at kunst mister sin rolle og legitimitet i det moderne samfund? Ikke nødvendigvis. En anden mulighed er, at kunst knyttes til den tilbageværende af de tre moderne utopier: arbejdets utopi og mere specifikt til dennes løfte om social forandring. Sammenknytningen af kunst og social forandring finder vi ikke så meget $i$ traditionen efter Kant som i en æstetisk tradition fra romantikerne over Friedrich Nietzsche til Gilles Deleuze (jf. Løhmann 43-50). Det er en æstetikteoretisk tradition, som bekymrer sig mindre om kunstens potentiale for kommunikation og fællesskab og fokuserer mere på den (ofte geniale éners) kreative skaben - en skaben, der også inkluderer evnen til at transcendere mainstream rationalitet, omvende alle værdier, skabe rum for en ukontrolleret mangfoldighed og pege ud over det eksisterende mod det nye.

Ser man på samtidskulturen, forekommer denne tradition stærkere end ovennævnte Kantianske tradition for at se et løfte om intersubjektiv kommunikation og fællesskab i kunsten. I hvert fald forbindes forestillingen om kunstnerisk praksis som et privilegeret sted for kreativiteten og det nye stadig oftere med forestillingen om arbejdet som et løfte om social forandring. Aktuelt er disse forbindelser helt centrale i legitimeringen af kunstens samfundsmæssige funktion.

Tydeligst er sammenkoblingen nok i den instrumentalisering af kunst, der ofte blev italesat som "de kreative erhverv" eller "den kreativ økonomi”. Den store interesse for creative industries begyndte i Storbritannien, da Tony Blairs New Labour fik regeringsmagten i 1997 (Løhmann I8I-2I8). Interessen bredte sig imidlertid hurtigt til andre dele af Europa, og også i Danmark kom der omkring årtusindskiftet en række tiltag, der skulle styrke den "kreative alliance" mellem handel, industri og kunst (Den kreative alliance, Danmarks kreative potentiale). Denne diskurs har siden stået stærkt, og der har været udbredt tendens til at se kreativitet som løsningen på næsten alle de problemer, vi kan møde i erhvervslivet, i nationaløkonomien, i organisationsudvikling, på uddannelsesinstitutionerne og i privatsfæren. I en bred vifte af diskurser præsenteres kreativiteten og dens løfte om nyhed eller innovation ikke blot som en vigtig egenskab ved kunst, men også som den eneste måde, hvorpå vi kan håndtere de aktuelle samfundsmæssige udfordringer. Kun ved at være kreative kan vi klare os i den globale konkurrence og undgå at blive væltet omkuld af de konstante forandringer i den "flydende modernitet" (Liquid 
Modernity). Dette betyder imidlertid også, at kreativitet ikke længere spiller en overskridende, undergravende eller antiautoritær rolle. Den er tværtimod en vigtig del af den postindustrielle, neoliberale økonomiske politik.

Det store fokus på kreativitet og forandring bekræftes af de franske sociologer Luc Boltanski og Eva Chiapellos udforskning af "kapitalismens nye ånd", Le nowvel esprit du capitalisme. Baseret på en omfattende empirisk undersøgelse af ledelseslitteratur argumenterer de for, at der fra I960'erne til I990'erne skete en signifikant ændring i kapitalismens normative system eller "legitimeringsregime”. I I990'ernes ledelseslitteratur finder de således en ny og indflydelsesrig legitimeringslogik. Med denne logik opfattes livet som en række nødvendigvis forskellige projekter, hvor forudsætningen for succes er, at man er fleksibel, kreativ, alsidig, mobil, aktiv og selvstændig. Man skal være i stand til og villig til at "tage chancer, skabe kontakt til nye mennesker, åbne nye muligheder, opsøge nyttige informationskilder og dermed undgå gentagelser" (Boltanski \& Chiapello I69). Mens den ideelle organisation i ledelseslitteraturen i I960'erne var en hierarkisk, meritokratisk og vertikal enhed, er den i 1990'erne en fleksibel, innovativ og projektorganiseret netværksorganisation præget af konstant forandring og baseret på selvstændige, kreative medarbejdere.

At kreativitet er en særdeles efterspurgt kvalitet på arbejdsmarkedet bekræftes også af de personlige profiler på det faglige netværk LinkedIn. I både 20II og 2012 var "kreativ" det mest brugte ord i de engelsksprogede profiler i samtlige medlemslande (Linkedin 20I2). I 20I3 lå "kreativ" også meget højt, dog nu på en tredjeplads efter de helt anderledes ladede "ansvarlig" og "strategisk". Til gengæld var "innovativ", som meget ofte er en del af kreativitetsdiskursen, rykket ind på top Io-listen (Linkedin 20I3). En meget stor del af LinkedIns mange medlemmer (stigende fra 135 millioner i 2011 til 259 millioner i 20I3) præsenterer altså sig selv som kreative. De udtrykker den legitimeringslogik, som Boltanski og Chiapello analyserer, og imødekommer den kreativitetsdyrkelse, som også artikuleres, når Bill Gates efterlyser en "kreativ kapitalisme" og Richard Florida i The Rise of the Creative Class hylder "den kreative tidsalder" og "det kreative samfund".

At kreativitet aktuelt er en helt central værdi, er endelig også synligt i vores æstetiske smags- og forbrugspræferencer. I de seneste 20 år har talrige kultursociologiske undersøgelser påpeget, hvordan der ikke længere er status i at have en eksklusiv, elitær smag. De vaner og præferencer, som i Bourdieus undersøgelse var udtryk for "god smag", bliver i dag anset for smalle og indskrænkede. I højsædet er nu en langt mere alsidig, eklektisk og fleksibel "altæder" (omnivorer), som sætter innovative eksperimenter og hybrider langt højere end perfektion inden for veldefinerede genrer (van Eijck 216). I dag er det ikke højstatus at have smag for en snæver og veletableret kulturel kanon. Den fleksible altæder er tværtimod åben for mangfoldige former, er særligt orienteret mod de nye og fremmede og evner selv at udvælge og kombinere på interessante og kreative måder. Den nye højstatussmag er dermed også én, der med sine altædende og skiftende kulturelle præferencer skaber grådige forbrugere og har en stærk allieret i markedet. Den er i det hele taget som skabt til - eller måske rettere af - en senmoderne verden, hvor fleksibilitet, mobilitet og kreativitet synes at være de vigtigste kriterier for succes.

\section{Utopiernes eksklusivitet}

Hvad jeg argumenterer for, er altså, at en ny kunstnerisk utopi er ved at vinde frem. Det er en utopi, hvor kunst ikke forbindes med demokratisk medborgerskab, men med kreativitet og med den forandring, der traditionelt har været knyttet til arbejdets utopi. I en lang række af samtidskulturens diskurser hyldes kunst primært for dens kreativitet og potentiale for social innovation, mens løfterne om kommunikation, fællesskab, frihed og lighed træder i baggrunden.

Spørgsmålet er, hvad dette har af æstetiske og sociale konsekvenser. Svaret er ikke helt enkelt. Man kan let påvise, at den klassiske kommunikative og civilisatoriske utopi ikke har ladet sig realisere på den måde, som Kant og traditionen efter ham tænkte det. Men den nye utopi om kreativitet og social innovation forekommer ikke mindre problematisk med hensyn til deltagelse. Hvis den klassiske utopis kommunikative fællesskab i teorien var åbent for alle, men kun blev virkeliggjort af en kulturel elite, så kan den nye utopi vise sig at være lige så elitær. Ideen om kunst som et middel til social innovation vil i realiteten meget nemt blive til en fejring af individuel forandring og kreativ selvrealisering. I den forstand kan den nye utopi blive endnu mere eksklusiv og monokulturel end den gamle.

Begge utopiske koblinger risikerer med andre ord at transformere ideen om det æstetiskes sociale potentiale til en realitet, der snarere handler om det ressourcestærke individs muligheder - i den kommunikative utopi i form af finkulturel dannethed og i den kreative utopi i fleksibel selvrealisering. Derudover er det iøjnefaldende, at mens utopien om kommunikativt fællesskab i hvert fald i de seneste årtier er blevet udfordret gennem forskellige sociale og symbolske magtkampe, så synes den nye utopi at udviske enhver antagonisme, når den fremstiller kreativitet ikke bare som en værdi, men som en nødvendighed for os alle. Det er endog meget svært at være modstander af fleksibilitet, innovation og forandring. Hvorfor skulle man dog det? En blind accept af disse værdier gør det imidlertid alt for nemt at overse, at fejringen af kreativitet meget ofte også er en fejring af det stærke individ. Vi beundrer de stærke, kreative mennesker, som indgår i alle mulige netværk og er i stand til at tilpasse sig eller endda skabe forandring. Dermed kræver vi im- eller eksplicit, at alle er konstant forandringsparate og i stand til at løse "deres egne" problemer individuelt og kreativt. Således ikke bare undgår vi, men tabuiserer også at genere hinanden og samfundet med problemerne - og gør det dermed sværere at løse systemiske problemer kollektivt. 


\section{Deltagelse som cestetikkens missing link?}

Spørgsmålet er nu, om æstetisk deltagelse kan være en løsning på problemerne i den kommunikative og kreative utopi. Igen er svaret ikke enkelt. I aktuel kunst og æstetikteori sker der dog en markant revitalisering af forestillingen om kunst som et særligt rum for eksperimenter med og udvikling af nye sociale deltagelsesformer. Under overskrifter som relationel æstetik, social æstetik, dialogisk, kollaborativ eller participatorisk kunst laves der talrige værker, forestillinger og udstillinger, afholdes konferencer og skrives artikler og bøger (jf. Bishop, Bourriaud, Kester). Men kan dette fokus på deltagelse være the missing link mellem fællesskabet og kreativiteten? Kan deltagelsens æstetik på én gang være et alternativ til det fællesskab, der blev transformeret til en snobbet og elitær monokultur, og den kreativitet, der kan være lige så eksklusiv og blind over for samfundsmæssige uligheder og modsætninger?

Umiddelbart er det i hvert fald indlysende, at interessen for deltagelse indoptager og omdanner elementer fra begge utopier. Dette sker ofte i et kapitalismekritisk vokabular, hvor kunst skal modvirke fremmedgørelse, neoliberalisme, isolation og magtesløshed. Især følgende elementer er iøjnefaldende (jf. Bishop, Participation I2; Kester 7-8): Først og fremmest er der en voksende interesse for kollektive, samarbejdende tilgange. Ofte, men ikke altid ledsages disse af en kritik af den individuelle kunstners autoritet og kontrol, idet kollaborativ kreativitet kobles til en mere demokratisk og mindre hierarkisk samfundsform. Yderligere sker der en bevægelse fra tekst-, billed- og objektbaserede værker til et arbejde med procesbaseret (erfaring med) deltagelse. Endelig er der ofte et eks- eller implicit ønske om empowerment. at erfaringen af at deltage i værket styrker deltagernes individuelle og/eller kollektive refleksion og handlekraft, og at dette modvirker isolation og styrker det sociale fællesskab. Agendaen for meget participatorisk kunst er altså ikke kun, at "publikum" skal deltage i værket, men også at værket skal deltage i samfundet. Mens folk deltager i det æstetiske, deltager det æstetiske i det sociale.

Når disse utopiske rekonfigurationer af kunstens forhold til det sociale gør kreativiteten kollaborativ og kombinerer individuel og kollektiv empowerment, æstetisk og demokratisk deltagelse, så forsøger de at tilbyde et alternativ til problemerne i hhv. den kommunikative og kreative utopi. Igen må man dog spørge til deltagelsesutopiernes gennemførlighed. Dette spørgsmål er så meget mere oplagt, fordi interessen for æstetisk/social deltagelse ikke er en ny opfindelse. Claire Bishop har således kaldt den aktuelle participatoriske strømning for en "tilbagevenden til det sociale” (Bishop, Artificial Hells 3), og hun og andre har påpeget strømningens forbindelser til den historiske avantgarde (især dadaismen og den russiske konstruktivisme/produktivisme) og til I960'ernes neoavantgarde (især situationisterne og arbejdet med fysisk deltagelse i teatersammenhænge). Yderligere har hun argumenteret for, at forsøgene på at tænke kunst kollektivt - i avantgarden, neoavantgarden og 1990 'erne - er forbundet med afgørende historiske udviklinger $i$ visionen om et kollektivistisk samfund: først med visionens triumf $i$ den russiske revolution i 1917, dernæst med dens heroiske sidste bastion i oprøret i 1968 og endelig med dens kollaps med Berlinmurens fald i 1989. Disse momenter blev, påpeger hun, alle fulgt af utopiske gentænkninger af kunstens politiske potentiale og forhold til det sociale (ibid.).

Ser man den aktuelle participatoriske kunst som en videreførelse af de sociale og politiske utopier i de tidligere avantgarde- og neoavantgardebevægelser, så vil optimismen med hensyn til, om den udgør æstetikkens missing link og kan løse problemerne i de andre utopier, formentlig være begrænset. Ligesom tilfældet var med den kommunikative og den kreative utopi, så har også avantgardens og neoavantgardens utopier vist sig svære at realisere på måder, der rækker ud over den konkrete kunstsituation og ind i det sociale.

Spørgsmålet er imidlertid, om vi bedst forstår de aktuelle forandringer via denne kunsthistoriske tilgang til deltagelseskunst. Man kan naturligvis godt på den aktuelle kunstscene finde ligheder til og videreudviklinger af bestemte participatoriske træk ved avantgarden og neoavantgarden. Men ser vi på den kulturelle kontekst, som den aktuelle revitalisering af deltagelsen foregår i, så bliver billedet et lidt andet. Så er det næppe, som Bishop foreslår, Berlinmurens fald, der har størst betydning for revitaliseringen. Rent bortset fra at Murens fald ikke kun repræsenterede et kollaps for kollektivismen, men i høj grad også var fremprovokeret af kollektive, ikkevoldelige bevægelser i Østeuropa, så har vi også siden 1990'erne set en fremvækst af en række nye kollektivistiske samfundsvisioner. Disse visioner finder ikke primært deres næring i politiske omvæltninger. De henter i stedet deres energi og forbilleder $\mathrm{i}$ internettet, Web 2.0 og de sociale forestillinger, der knytter sig til disse.

\section{Kreativ kollektiv deltagelse}

Når internettet og senere Web 2.0 er afgørende for at forstå deltagelseskunstneriske praksisser, skyldes det, at de nye netværk og medier afgørende forandrer vores måde at kommunikere og være kreative på. Web 2.0 ændrer ikke bare vores praksis i forhold til bestemte nye medier, men gennemtrænger vores hverdagsliv i en grad, så det også forandrer vores opfattelse af mange andre fænomener, herunder ikke mindst kommunikation og kreativitet. Med de mobile og allestedsnærværende medier ændres vilkårene for og synet på kommunikation og kreativitet, og dermed også på kunst og socialitet. Hvis kunst bl.a. er karakteriseret ved at være kommunikation og kreation, så betyder det noget for (opfattelsen af) kunsten, når (opfattelsen af) vores kommunikative og kreative praksis ændrer sig. I dag er det således tydeligt, at en traditionel romantisk kunstopfattelse passer temmelig dårligt til de nye vilkår. Hvis en traditionel kunstlogik indebar, at en kunstner skabte et afgrænset, fuldendt og autonomt værk, som blev distribueret, formidlet og/eller solgt til publikum gennem eksklusive kunstinstitutioner som museer, koncertsale og kunsthandlere, så konfronteres vi nu i stadig stigende grad med en logik, der udspringer af de nye medier. Det er en logik med kollaborative forfatterskaber (f.eks. i Wikipedia), med en udviskning af den klare grænse mellem produktion og reception (jf. begreber som produser og prosumer), og med artefakter, der kopieres, 
imiteres, remixes, jammes og modificeres på mangfoldige måder (f.eks. videoer på YouTube). Sidst, men ikke mindst er det en logik, hvor artefakter deles via sociale netværk og ofte er særdeles let tilgængelige.

Disse karakteristika ved vores omgang med de nye medier kan i stort omfang genfindes i de aktuelle deltagelseskunstneriske praksisser on- og offline. Således har Nicolas Bourriaud i Postproduction (2007) beskrevet, hvordan kunst reprogrammerer verden ved at udvælge, kombinere, bruge, redigere, manipulere osv. Og Beryl Graham har i "What kind of participative system?" (2010) foreslået, at vi beskriver kunstværker ud fra den deltagelse, de muliggør: at vi i stedet for at fokusere på, hvilke medier de benytter sig af, beskriver dem ud fra den ageren, de lægger op til, og analyserer deres specifikke former for interaktivitet, deltagelse og "konnektivitet" (Graham 284).

Danske Superflex er et eksempel på en kunstnergruppe, der i vidt omfang bruger de nye mediers logikker og praksisformer. Superflex skaber i deres eget vokabular ikke kunstværker, men tools eller værktøjer. Disse værktøjer retter sig i høj grad mod sociale og økonomiske problemer i verden og kan ofte bruges til at udfordre national politik eller multinationale virksomheders interesser, f.eks. ved at iværksætte kollektive delingsøkonomier og konkret hævde de fælles rettigheder i forhold til private interesser. Superflex producerer ikke repræsentationer, men værktøjer eller interventioner, som både bygger på, lægger op til og tematiserer deltagelse. Et eksempel er "Til offentlig brug" (2004), en gratis stencil, hvormed man kan spraye netop disse ord på noget, som er/bør være til offentlig brug (Superflex. For public use). Et andet er "Supercopy Factory", som kan (silke)trykke "SUPERCOPY" på falske mærkevarer som LaCoste poloshirts og Louis Vuitton-tasker (2002 \& 2007) og dermed skabe ny originaler (Superflex. Supercopy Factory).

Superflex er tættere på en ny medielogik end på en traditionel kunstlogik, når gruppen definerer sig selv som "en kunstner med 6 ben" (Superflex. An artist with 6 legs), og når den med sine værktøjer udfordrer grænsen mellem privat og offentligt eller mellem original og kopi. Man kan naturligvis indvende, at kunstnere i virkeligheden aldrig har været ene om kunstproduktionen. Som Howard Becker argumenterede for allerede i "Art as collective action" fra 1974, samarbejder stort set alle kunstnere med en række andre aktører eller støttepersoner i den konkrete produktionsproces. Og for alle kunstnere gælder det, at kreative valg ikke tages uafhængigt af en tradition, men i forhold til en række ofte internaliserede konventioner om f.eks. materialer, temaer, abstraktioner, formater og forhold til publikum (jf. Becker). I dag er Beckers fremstilling af kunst som en kollektiv handling imidlertid langt mindre kontroversiel, end da han skrev den. Nu er det nok snarere tanken om helt individuel kreativitet, der forekommer ude af trit med vores hverdagserfaring, mens kollektiv kreativitet ikke synes nær så utopisk, som den gjorde, da de russiske avantgardister ville forvandle fabrikkerne til steder for kollektiv kreativitet, eller da Joseph Beuys neoavantgardistisk hævdede, at alle mennesker er kunstnere (Bishop, Participation I25).
Naturligvis kan man stadig finde fortalere for kvalitets- og autoritetskontrollen i den traditionelle kunstlogik og de traditionelle medier. Eksempelvis har Andrew Keen i The Cult of the Amateur argumenteret for, at de nye medieplatformes demokratisering $i$ virkeligheden er en forfladigelse, hvor professionalisme fortrænges af amatørisme, originalitet af dårlige kopier, kvalitet af kvantitet, sandhed af tvivlsom pålidelighed og fokuseret opmærksomhed af en overvældende mængde af ligegyldigheder. Til gengæld har mange andre teoretiker som f.eks. Pierre Lévy, Howard Rheingold, Henry Jenkins, Charles Leadbeater og David Gauntlett med stor entusiasme hyldet de demokratiske og sociale potentialer i Web 2.o's kollektive intelligens og kreativitet.

Fælles for alle disse teoretikere er, at de meget eksplicit forbinder kommunikation og fællesskab på den ene side og kreativitet og forandring på den anden. Når Gauntlett kan kalde sin bog fra 20II for Making is Connecting, så er det, fordi han undersøger og argumenterer for kreativitetens sociale betydning. Og når Leadbeaters bog fra 2009 har titlen We-Think: The Power of Mass Creativity, så skyldes det, at han skriver om, hvad vi kan med kollaborativ kreativitet - ikke fordi individuel kreativitet ikke findes, men fordi kreativitet ikke er at skabe ex nibilo, men at kombinere forskellige elementer på nye måder. I den forstand bygger både Gauntlett og Leadbeater videre på Pierre Lévy, som foregreb mange senere diskussioner, da han i L'intelligence collective: pour une anthropologie du cyberspace (1994) beskrev intelligens som kollektiv. Lévy arumenterede her for, at vi alle arver og profiterer fra den viden, de institutioner og de symbolske og materielle værktøjer, der er akkumuleret i samfundet, og at de mest avancerede samfund baserer sig på institutioner, der bygger på kollektiv intelligens i form af velordnede konversationer. Ifølge ham er det netop for at udnytte den kollektive intelligens, at avancerede samfund satser på demokrati frem for diktatur, frit marked frem for planøkonomi og videnskabens peer-to-peer-udvekslinger frem for dogmatikkens givne hierarkier.

I nærværende artikels optik er ovenstående teoretikeres påpegning af en civiliseret, social og kreativ konversation vigtig. Når de på én gang udforsker den nye "konnektivitet" i kommunikationen og fremhæver det kollektive i kreativiteten, udpeger de en måde, hvorpå man måske kan undgå den elitære dannethed eller individualisering, som de kommunikative og kreative utopier ellers let havner $i$. Naturligvis er der ingen garantier. Også på Web 2.0 er der store uligheder med hensyn til deltagelse - jf. den mere eller mindre velunderbyggede antagelse om en I-9-9O-regel: at I\% af brugerne på de sociale medier producerer originalt materiale, $9 \%$ kommenterer, mens 90\% kun ser og læser. Nogle af teoretikerne tematiserer heldigvis også denne ulighed (jf. Jenkins Confronting the Challenges), men flere går let hen over den i deres begejstring for den digitale deltagelses kreative og kommunikative potentialer. 


\section{Deltagelsens vilkår og former}

Netop i forhold til forskelle og uligheder i deltagelsen forekommer det mig, at de participatoriske kunstpraksisser har noget at byde på. Det mest interessante ved deres eksperimenter med deltagelse er i denne artikels optik ikke, når de prøver at etablere møder, samtaler og sociale relationer, der kan fungere som mikroutopier $i$ en samfundsmæssig kontekst domineret af markedsgørelse, ensretning, neoliberalisme etc. (jf. Bourriaud 2005). Som Bishop og andre har argumenteret for, vil en participatoriske kunstpraksis, der forsøger at skabe mikroutopier i form af positive relationer og inkluderende dialoger, alt for ofte ignorere konflikter og magtrelationer (jf. Bishop Artificial Hells). Eksempelvis er det at servere suppe for gæsterne på et galleri ikke bare forbeholdt en eksklusiv gruppe; som kunsthandling ignorerer det også sin egen eksklusivitet.

Skal deltagelseskunstneriske praksisformer fungere som æstetikkens missing link, eller mere beskedent: skal de pege ud over det elitære i hhv. den kommunikative og kreative utopi, så skal de nødvendigvis konfrontere disse utopiers problemer, herunder ikke mindst deres eksklusivitet. Måderne at gøre dette på er mangfoldige, og jeg skal kort udpege tre eksempler. Det første er den spanske kunster Santiago Sierra, som konsekvent arbejder med grænserne og vilkårene for deltagelse både i kunstverdenen og i samfundet. I 2003 repræsenterede han Spanien på Venedig Biennalen ved at mure hovedindgangen til den spanske pavillon til og kun give adgang for personer med spanske identitetspapirer. Han har også lavet en række performances, hvor han bruger socialt udsatte grupper som f.eks. immigranter til at lave umiddelbart meningsløst, dårligt betalt og stærkt ubehageligt arbejde som at bo bag en mur, sidde skjult i en papkasse, understøtte en stolpe eller blive sprayet til med skum, som stivner (Santiago Sierra).

Det andet eksempel er igen Superflex. I 20I3 blev kunstnergruppen af dagbladet Politiken og Kommunernes Landsforening inviteret til at deltage i nogle debatarrangementer om "Det lokale demokrati” på Folkemødet på Bornholm d. I3.-I6. juni. Superflex løste opgaven ved at lave "Kontrakt om deltagelse": to kontrakter om hhv. aktiv eller passiv deltagelse med hver sit sæt af forpligtelser for deltagere og arrangører. Inden debatarrangementernes begyndelse skulle tilhørerne underskrive en kontrakt om enten "ved egen drift at søge at påvirke denne debat" eller "ikke at deltage i debatten, hverken verbalt eller ved fysisk gestikuleren". Tilsvarende skulle arrangørerne forpligte sig på at lade underskriverne af den førstnævnte kontrakt komme til orde og ikke at afkræve aktiv deltagelse af underskriverne af den anden (Superflex, Participation Contract). Sidst, men ikke mindst var der på selve mødet opstillet et hegn, som fysisk adskilte dem, der havde lovet at deltage aktivt, fra dem, der havde lovet at være passive.

Sidste eksempel er den tyske instruktør Lukas Matthaeis War - du skulle have veret der, som bl.a. blev opført under Viborg Festuge i september 20I3. Dette stedsspecifikke teaterstykke om Danmarks deltagelse i krigen i Afghanistan arbejdede med deltagelse på en række forskellige niveauer: ved at inddrage lokale Viborgensere (og steder) i produktionen; ved gennem lydoptagelser af en soldats, en feltpræsts og en krigsfotografs personlige stemmer at berette om meget forskellige former for krigsdeltagelse; ved at sammenligne deltagelsen i Danmarks hær, i et soldaterfællesskab, der også omfattede "fjenden", og i en almenmenneskelighed; og ved at lade tilskuerne få del i soldaternes udsathed og traumer, ikke bare auditivt og visuelt, men også ved kropsligt at mærke udsatheden i forskellige rum: det tomme fodboldstadion oplyst af stærke projektører og betonkælderen opfyldt af høj heavy metal.

Sierra, Superflex og Matthaei arbejder med deltagelse på meget forskellige måder. Deres værker er alle kollektive, men ingen af dem er det i forhold til tilskueren på en venlig, inkluderende, positiv måde. Tvært imod giver de konkret form til konflikterne og uligheden i deltagelsen og de rammer, der æstetisk og politisk sættes for den. Snarere end at invitere, provokerer de til dialog, samtidig med at de begrænser dennes muligheder med en mur, et hegn eller hård, øredøvende musik. Og vigtigst i forhold til deltagelse lader de os ikke bare se uligheden og eksklusionerne, men får os også til at opleve vores eget ansvar for dem. Hos Sierra sker det, når den spanske pavillon får os til at mærke, hvordan vi tilhører de privilegerede lande og mennesker, der har adgang til den internationale kunstverden og nyder godt af underbetalte arbejdere. I Superflex' "Kontrakt om deltagelse" bliver de aktive skilt fra de passive på en måde, der er lige ubehagelig på begge sider af hegnet. $\mathrm{Og}$ i Matthaeis "War - du skulle have været der" bliver det konkret sanseligt, at vi var der, i Afghanistan, uanset om vi skulle have været der eller ej - Danmark deltog i krigen, mens Afghanistan kun i meget begrænset omfang og redigeret form tager del $i$ vores liv og offentlighed.

Hvis deltagelseskunstnerisk praksis kan noget, så er det måske det, som disse værker gør: ikke bare at have tillid til, at kreativ, kollektiv og kommunikativ deltagelse nødvendigvis er af det gode, men at tydeliggøre, udforske og udfordre deltagelsens uligheder, konflikter og eksklusioner. Når det sker, så tror jeg faktisk, at eksperimenterne med forskellige deltagelsesformer kan pege ud over nogle af problemerne i de kommunikative og kreative utopier - ikke ved at gøre deltagelsen til en ny utopi, men tvært imod ved at vise, hvorfor deltagelse og fællesskaber ikke altid er en feel-good-ting: bl.a. fordi der er noget, der forhindrer deltagelse; nogen, der ikke deltager; og noget, vi slet ikke skal deltage i.

\section{LITTERATURLISTE}

Andreson, Benedict. Forestillede fallesskaber. Frederiksberg: Roskilde Universitetsforlag 20oI. Bauman, Zygmunt. Culture in a liquid modern world. Cambridge: Polity, 20II.

Bauman, Zygmunt. Liquid Modernity. Cambridge: Polity Press 2000.

Becker, Howard S. "Art as Collective Action". American Sociological Review, vol 39, no 6, 1974.

Bishop, Claire. Artificial Hells. Participatory art and the politics of spectatorship, London: Verso 2012. 
Bishop, Claire (red.). Participation. London: Whitechapel Gallery 2006.

Boltanski, Luc og Eve Chiapello. "The New Spirit of Capitalism”. International Journal of Politics,

Culture, and Society, vol. 18, nr. 3/4 (2005): 16I-188.

Bourdieu, Pierre. La distinction. Paris: Éditions de Minuit 1979.

Bourriaud, Nicolas. Postproduction. New York: Lukas \& Sternberg 2007.

Bourriaud, Nicolas. Relationel astetik. Kbh.: Det Kongelige Danske Kunstakademi 2005.

Danmarks kreative potentiale - kultur-og erhvervspolitisk redegorelse 200o. Erhvervsministeriet \&

Kulturministeriet. November 200o. http://kum.dk/Documents/Publikationer/200o/Danmarks\%20

kreative\%2opotentiale/Danmarks\%2okreative\%2opotentiale.pdf

Danskernes kulturvaner 20I2, Epinion A/S og Pluss Leadership A/S, Kulturministeriet 20I2.

Den kreative alliance. En analyse af samspillet mellem kulturlivet og erbvervslivet. Økonomi- og

erhvervsministeriet \& Kulturministeriet. September 20oo. http://www.cko.dk/sites/default/files/ den_kreative_alliancer.pdf

Eijck, K. van. "Richard A. Peterson and the culture of consumption". Poetics 28:2 (2000): 207-224

Ejgod, Louise. Hvad er publikumsudvikling? 2012, http://pure.au.dk/portal/files/45656795/Rapport_I publikumsudvikling.pdf.

Forfatter. 20II. 139-162

Florida, Richard. The Rise of the Creative Class: and How It's Transforming Work, Leisure, Community and Everyday Life. New York: Basic Books, 2002.

Gates, Bill. “World Economic Forum 2008”. Microsoft News Center 24. januar 2008. Web 9. april 2014 http://www.microsoft.com/en-us/news/exec/billg/speeches/20o8/oI-24wefdavos.aspx

Gauntlett, David. Making is Connecting: The Social Meaning of Creativity, from DIY and Knitting to YouTube and Web 2.o. Cambridge: Polity Press, 20II.

Graham, Beryl. "What kind of participative system? Critical vocabularies fom new media art". The 'do-ityourself artwork. Red. Anna Dezeuze. Manchester: Manchester University Press 2010

Jenkins, Henry. Convergence Culture: Where Old and New Media Collide. New York: New York University Press 2006.

Jenkins, Henry m.fl.: Confronting the Challenges of Participatory Culture: Media Education for the 2Ist Century, 2009. http://mitpress.mit.edu/sites/default/files/titles/free_download/97802625I3623 Confronting_the_Challenges.pdf

Kant, Immanuel. Kritik af dommekraften. København: Det lille forlag 2007.

Keen, Andrew. The Cult of the Amateur. New York: Doubleday/Currency 2007.

Kester, Grant. The One and the Many. Contemporary Collaborative Art in a Global Context. Durham/ London: Duke 20II

Leadbeater, Charles. We-Think: The Power of Mass Creativity. London: Profile 2009.

Lévy, Pierre. L'intelligence collective: pour une anthropologie du cyberspace. Paris: La Découverte, 1994.

Linkedin 20I2, "Top Io Overused Professional Buzzwords 20I2", 4. december 20I2. Web 9. april 2014. http://blog.linkedin.com/20I2/r2/04/buzzwords-20I2/

Linkedin 2013, "Top Io Overused LinkedIn Profile Buzzwords of 2013”, II. december 20I3. Web 9. april 20I4. http://blog.linkedin.com/2013/212/r/buzzwords-2013/
Michaud, Yves. "The End of the Utopia of Art". Think Art. Theory and Practice in the Art of Today. Red. Bartomeu Mari \& Jean-Marie Schaeffer. Rotterdam: Witte de With Center for Contemporary Art 1998.

Pariser, Eli. The Filter Bubble: What the Internet Is Hiding from You. London: Penguin 20II.

Peterson, Richard A. "Problems in comparative research: The example of omnivorousness". Poetics $33: 5$ (2005): 257-282

Reach Out! - inspiration til brugerinddragelse og innovation i kulturens verden. Kulturministeriets tværgående projektgruppe. September 2008. http://kum.dk/Documents/Publikationer/2008/ Reach_Out/pdf/ReachOut_Web.pdf

Reach Out Inspirationskatalog - naviger i brugerinddragelse og brugerdrevet innovation. Center for Kultur og Oplevelsesøkonomi og Kulturministeriet. April 20I2. http://kum.dk/Documents/ Publikationer/20I2/reachout20I2.pdf

Santiago Sierra. Wep I8. september 20I4. http://www.santiago-sierra.com/index_I024.php. Schulze, Gerhard. Die Erlebnisgesellschaft: Kultursoziologie der Gegenwart. Frankfurt: Campus 1993.

Stephensen, Jan Løhmann. Kapitalismens and og den kreative etik. Aarhus: Digital Aesthetics Research Center 2010

Superflex. An artist with 6 legs. Web I4. maj 20I4. http://superflex.net/tools/xxxxxxxxx_an_artist_ with_6_legs

Superflex. Participation contract. Web I4. maj 20I4. http://superflex.net/tools/participation_contract Superflex. For public use. Web I4. maj 20I4. http://superflex.net/tools/for_public_use Superflex. Supercopy Factory. Web I4. maj 20I4. http://superflex.net/tools/supercopy_factory

Tepper, Steven J. \& Bill Ivey (red.). Engaging Art. The Next Great Transformation of America's Cultural Life. New York/London: Routledge 2008.

War - du skulle have varet der. Web I4. maj 20I4. https://www.youtube.com/watch?v=k2sflaozAHc. 
